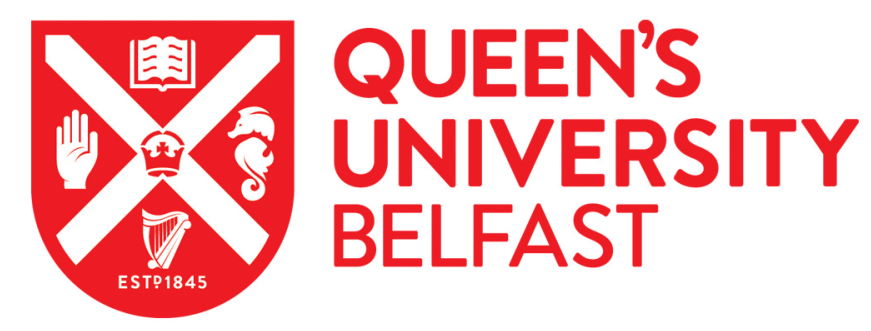

\title{
Cancellous bone repair using bovine trabecular bone matrix particulates.
}

Mushipe, M. (2002). Cancellous bone repair using bovine trabecular bone matrix particulates. Biomaterials, 23(2)(2), 365-370. https://doi.org/10.1016/S0142-9612(01)00114-4

\section{Published in:}

Biomaterials

\section{Queen's University Belfast - Research Portal:}

Link to publication record in Queen's University Belfast Research Portal

\section{General rights}

Copyright for the publications made accessible via the Queen's University Belfast Research Portal is retained by the author(s) and / or other copyright owners and it is a condition of accessing these publications that users recognise and abide by the legal requirements associated with these rights.

Take down policy

The Research Portal is Queen's institutional repository that provides access to Queen's research output. Every effort has been made to ensure that content in the Research Portal does not infringe any person's rights, or applicable UK laws. If you discover content in the Research Portal that you believe breaches copyright or violates any law, please contact openaccess@qub.ac.uk. 


\title{
Biomaterials
}

Biomaterials 23 (2002) 365-370

www.elsevier.com/locate/biomaterials

\section{Cancellous bone repair using bovine trabecular bone matrix particulates}

\author{
M.T. Mushipe ${ }^{\mathrm{a}, *}$, P.A. Revell ${ }^{\mathrm{b}}$, J.C. Shelton ${ }^{\mathrm{a}}$ \\ ${ }^{a}$ IRC in Biomedical Materials, Queen Mary, University of London, Mile End Road, London, E1 4NS, UK \\ ${ }^{\mathrm{b}}$ IRC in Biomedical Materials, Royal Free and University College Medical School, University College London, \\ Department of Histopathology, Royal Free Hospital, Pond Street, London, NW3 2QG, UK
}

Received 11 April 2000; accepted 13 March 2001

\begin{abstract}
At 5 and 15 weeks post-surgery, biomechanical and histological analyses of cancellous bone defects filled with the bovine trabecular bone matrix (BBM) and hydroxyapatite (Hap) particulates of dimensions 106-150 $\mu$ m were investigated. It was observed that at 5 weeks post-surgery the stiffness properties of the BBM filled defects were significantly higher than those observed in the Hap filled defects $(p<0.01)$ but comparable to those recorded in intact cancellous bone from the same anatomical position. Histologically, no significant differences were observed in the percentage of new bone contact with the particles. The biomechanical properties of the Hap filled defects mirrored those in intact cancellous bone only at 15 weeks post-surgery. BBM particles thus appeared to accelerate the early healing of osteotomies. It is therefore suggested that particles of this bioceramic be the subject of intense research for more usage in both periodontal osseous defects and orthopaedic fractures. C) 2001 Elsevier Science Ltd. All rights reserved.
\end{abstract}

Keywords: Bone repair; Bovine trabecular bone matrix; Hydroxyapatite; Particulates; Mechanical properties

\section{Introduction}

The number of bone grafts performed in the USA annually exceeds 100,000 [1]. There is therefore considerable interest in enhancing normal repair processes and minimum open surgery is imperative [2-4]. With several advantages over either autografts, allografts or xenografts, alloplasts can be very effective bone substitutes [5-11]. For instance, the transmission of antigens is avoided and the quantity of the biomaterial is relatively abundant [12]. In addition, with particulates, the surface area for more chemical and biological reactions to take place is increased. Therefore interaction between the newly formed bone and the biomaterial is intensified, analogous to the rapid vascularisation and incorporation of bone pieces used in bone grafting [13].

\footnotetext{
*Corresponding author. Current address: School of Mechanical and Manufacturing Engineering, Queen's University Belfast, Ashby Building, Stranmillis Road, Belfast BT9 5AH, UK. Tel.: +028-90274509; fax: + 028-90-661729.

E-mail address: m.mushipe@qub.ac.uk (M.T. Mushipe).
}

The use of dispersed particles as opposed to blocks of porous biomaterials also circumvents the problem of stress protection. If the implant remains strong the newly generated bone is shielded from external forces and osteogenesis is considerably affected [12]. Hing [14] observed that the biomechanical properties of bovine trabecular bone matrix (BBM) blocks of apparent density range, $1.09-1.38 \mathrm{Mg} \mathrm{m}^{-3}$, exhibited the same mechanical behaviour throughout the implantation period, thus were unaffected by the newly formed bone. At 6 months post-surgery, the new bone-bioceramic composite in the distal femoral condyles of rabbits in the centre of the patellar groove exhibited the same biomechanical properties as the bioceramic before implantation.

In this study, the effects of two bioceramics on the repair of cancellous bone defects were investigated. It was hypothesised that the provision of mineral particulates at the defect site would enable the defect to heal more rapidly than an empty, untreated defect. The critical healing stage was regarded as the restoration of 


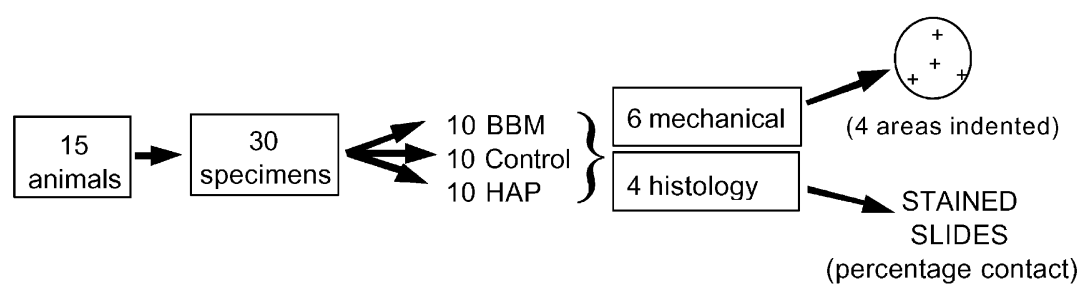

Fig. 1. Allocation of treatments and analyses of animals and specimens at each observation time.

stiffness, although other, biological parameters were also considered.

\section{Materials and methods}

\subsection{Implant materials}

A macroporous apatite prepared by the hydrothermal conversion of bovine cancellous bone in the distal and proximal ends of the femur and the humerus, BBM (E. Merck, Germany) and a commercial hydroxyapatite (Hap), powder, P120 (Plasma Biotal, UK) were used.

Porous blocks (apparent density range, 0.51$1.38 \mathrm{Mg} \mathrm{m}^{-3}$ ) of BBM were crushed using a pestle and mortar, sieved through standard wire cloth sieves of 106 and $150 \mu \mathrm{m}$ and the microparticles within this range collected for implantation. Hap particles were obtained from sintered Hap powder (nominal diameter of $3.29 \mu \mathrm{m})$. The powder was initially compacted in a stainless steel die and then compressed at a pressure of $140 \mathrm{MPa}$ using an hydraulic press. The dense compacts were then sintered at $1200^{\circ} \mathrm{C}$ (the heating and cooling rate of the furnace was $4^{\circ} \mathrm{C} \mathrm{min}{ }^{-1}$ ) and the dwell time at maximum temperature was $4 \mathrm{~h}$. After sintering the dense material was crushed and particles $(150-212 \mu \mathrm{m})$ were collected and milled at a tumbler setspeed of 2 for $90 \mathrm{~min}$ (Pascall Engineering, England) before final collection of particles, $106-150 \mu \mathrm{m}$ for implantation.

Chemical analyses were performed using the Siemens D-5000 X-ray diffractometer with graphite monochromated $\mathrm{Cu}-\mathrm{K}_{\alpha}$ radiation and $2 \theta$ ranged from $5^{\circ}$ to $110^{\circ}$, with $0.02^{\circ}$ step sizes at $12 \mathrm{~s}$ per step. In addition, diamond paste polished specimens embedded in Technovit 7200 VLC resin (Kulzer and Co., Germany) were evaluated using energy-dispersive electron-probe $\mathrm{X}$-ray analysis (EDAX) with an electron beam maintained at $2 \times 10^{-10} \mathrm{~A}$, the accelerating voltage at $10 \mathrm{kV}$ and the X-ray intensity in counts per seconds, recorded.

\subsection{Surgical procedure}

Before implantation, all particulates were sterilised by autoclaving at $121^{\circ} \mathrm{C}$ for $20 \mathrm{~min}$ and the guidelines for the care and use of laboratory animals (Animals (Scientific Procedures) Act 1986) were observed. Thirty female, New Zealand white rabbits (average weight, $2.98 \mathrm{~kg}$, range $2.6-3.4 \mathrm{~kg}$ ) were operated bilaterally, see Fig. 1. To impose total impartiality, a protocol for the selection of the animals and the assignment of three study groups was developed before the animals were brought into the operating room. After induction with intravenous Diazemil $\left(0.1 \mathrm{ml} \mathrm{kg}^{-1}\right)$ and Hypnorm $\left(0.5 \mathrm{ml} \mathrm{kg}^{-1}\right)$, the animals were shaved, disinfected using aqueous Betadine ${ }^{\circledR}$, draped and anaesthesia was maintained with a $1: 1$ mixture of oxygen and nitrous oxide with $2-3 \%$ halothane. The femoral condyle was located by palpation and an incision, $20-30 \mathrm{~mm}$ long, was made on the lateral side of the knee through the skin to expose the underlying muscles and tendons, and the underlying femoral condyle. Using a slow speed, diamond edged, hollow trephine attached to a pneumatic drill, with profuse saline solution irrigation, defects, $4.5 \mathrm{~mm}$ in diameter and $3 \mathrm{~mm}$ in depth, were created and filled with BBM or Hap particles or left untreated as empty controls. The soft tissue and skin incisions were closed using interrupted suturing.

The animals were kept in groups of five and were allowed to run freely in a pen. Low fat dry pellet, SDS rabma (Essex, England), hay and water ad libitum were provided. At 5 and 15 weeks post-surgery, the animals were sacrificed by intravenous administration of an overdose $(5 \mathrm{ml})$ of pentobarbitone sodium BP (Expiral; $200 \mathrm{mg} \mathrm{ml}^{-1}$ ). To view the defect position, anteroposterior and medial-lateral macroradigraphs were taken at $30 \mathrm{kV}, 2 \mathrm{~mA}$ and 3 mins of exposure, with a Hewlett Packard Faxitron 43804N cabinet X-ray system (Vinten Instruments Ltd., England) on AGFA films. Before mechanical testing the specimens were wrapped in paper soaked with phosphate buffered Ringer's solution at $37^{\circ} \mathrm{C}$ and the histology specimens were stored in alcoholic formaldehyde (formal/alcohol).

\subsection{Mechanical testing}

Indentation tests were performed on a mechanical testing machine (Instron 4464, $2.5 \mathrm{~N}$ load cell, Instron, UK) within the first $24 \mathrm{~h}$ post-euthanasia. Using a hemispherical stainless steel indenter of $1.5 \mathrm{~mm}$ in diameter 4 areas were loaded to $2 \mathrm{~N}$ at $6 \mathrm{~mm} \mathrm{~min}^{-1}$ on 
each specimen, see Fig. 1. The load and displacement responses were measured by the in-built devices and recorded. The properties of intact cancellous bone from the same anatomical position were also determined.

\subsection{Histology}

After 1 week fixation in alcoholic formaldehyde the implant blocks were dehydrated in $100 \%$ industrial methylated spirit, IMS as follows; $48 \mathrm{~h}$ in IMS on a stirring plate under vacuum pressure $600 \mathrm{mbar}$, then $24 \mathrm{~h}$ in fresh IMS, followed by $24 \mathrm{~h}$ in chloroform to remove fatty deposits and finally $24 \mathrm{~h}$ in fresh IMS.

After dehydration, the implant blocks were infiltrated and embedded in plastic resin, LR White (London Resin Co. Ltd., UK). Infiltration was carried out in two 48-h sessions and polymerisation was performed for $24-36 \mathrm{~h}$ at $55^{\circ} \mathrm{C}$. The undecalcified blocks were glued to plastic slides using Technovit 4000 and Pulver resin mixture (Kulzer and Co., Germany). Each block was sectioned perpendicular to the longitudinal axis of the femur using a diamond band saw on an Exakt cutting machine (Exakt Corp., Germany). Slices, 150-200 $\mu \mathrm{m}$ thick, mounted on plastic slides with the light-curing resin Technovit 7200 VLC (Kulzer and Co., Germany), were obtained. Sections were then ground from these to 60$70 \mu \mathrm{m}$ thickness with the Exakt grinding machine (Exakt Corp., Germany) and stained with toluidine blue and von Kossa stains.

\subsection{Analysis of results}

Test compliance properties were removed from the raw data and a third order polynomial was subsequently used to describe the data. The equation was used to determine the tangential stiffness at $1.9 \mathrm{~N}$, thus minimising the observer bias.

Using the stained histological sections, light microscopic histomorphometry was performed on a Leica DMRB microscope (Leica Corp., UK), connected to a Sony 3 CCD colour video camera (Sony Corp., Montvale, NJ), and Leica image analysis software (Leica Corp., UK) to determine the percentage bone contact, i.e., length of the surface implanted granules directly contacted by bone divided by the total surface length of the same granules multiplied by $100 \%$.

After testing data for normality [15], analysis of variance and the unpaired 2-sided Student's $t$-test, assuming unequal variances were performed on normally distributed mechanical data whereas KruskalWallis and Mann-Whitney tests were used to compare skewed histological data (Minitab 7.2, Minitab, Inc., 1989). Differences were considered statistically significant at $p<0.05$.

\section{Results}

The animals were fully mobile and weight-bearing within 1-2 days post-surgery, and thus recovered very well, with the exception of one from the 5-week and 2 from the 15-week periods which were sacrificed before the end of the planned observation periods. The 5-week animal had developed an abscess in the knee joint that lead to reduced extension of the limb, resulting in lameness. Post-mortem examination of various internal organs obtained from the other two animals, revealed that one animal had developed pneumonia, and the other animal had distended loops of intestine and a form of peritonitis.

\subsection{EDAX and $X$-ray analysis}

The XRD patterns showed that BBM and Hap had similar crystallinity structures but different unit cell dimensions. The $a$-axis of BBM, $9.413 \times 10^{-1} \mathrm{~nm}$, was longer than those of the Hap, $9.408 \times 10^{-1} \mathrm{~nm}$, consequently, the $c$-axis value for the two ceramics $\left(6.879 \times 10^{-1}\right.$ and $6.882 \times 10^{-1} \mathrm{~nm}$, respectively) were reversed.

\subsection{Mechanical results}

The tangential stiffness values of the healing defects are shown in Table 1. Indentation results from the peripheral tests, see Fig. 1, are reported because centre test data were observed to be significantly different from the former. Out of a possible $18 n$ values, (i.e. 3 tests times 6 specimens) for each observation group, only a fraction of the indentation data are reported, discrepancy was attributed to failures in determining data from the polynomial equation that was employed.

Table 1

Tangential stiffness values $(\mathrm{kN} / \mathrm{m})$ of healing defects at 5 and 15 weeks post surgery

\begin{tabular}{llcc}
\hline Observation group & Parameter & \multicolumn{2}{c}{ Observation time } \\
\cline { 3 - 4 } & & 5 weeks & 15 weeks \\
\hline BBM & Mean & 171.6 & 154.2 \\
& sem $^{\text {a }}$ & 33.3 & 39.8 \\
Control & $n$ & 11 & 12 \\
& Mean & 80.2 & 134 \\
\multirow{3}{*}{ Hydroxyapatite } & sem & 17.1 & 23.9 \\
& $n$ & 9 & 15 \\
& Mean & 49.2 & 126.7 \\
Intact bone & sem & 8.70 & 23.7 \\
& $n$ & 11 & 10 \\
& Mean & 132.4 & 128.1 \\
& sem & 13.5 & 28.6 \\
& $n$ & 16 & 5 \\
\hline
\end{tabular}

${ }^{\mathrm{a}}$ sem $=$ standard error of the mean. 
Analysis of variance of the observation groups revealed that at 5 weeks post-surgery there were significant differences among the observation groups $(p<0.001)$. Significant differences were observed between the control group and both the BBM and intact bone groups $(p<0.05)$, but not the Hap group. The stiffness of the Hap filled defects was observed to be significantly different from both the intact bone $(p<0.001)$ and the BBM filled defects $(p<0.01)$. No statistical differences were observed between the BBM filled defects and the intact bone at 5 weeks post surgery. Comparisons between 5- and 15-week observation groups showed that the stiffness values increased significantly only in the control $(p<0.01)$ and Hap filled defects $(p<0.001)$. No significant differences were observed between the observation groups at 15 weeks post-surgery.

\subsection{Histomorphometry results}

At both 5 and 15 weeks post-surgery there was intimate contact between the newly formed bone and the bioceramics with no evidence of intervening layers of fibrous tissue. The particulates were osteoconductive and both osteocytes and osteoblasts were ubiquitous in the new osseous tissue (Fig. 2).

The effects of the apatites on the apposition of bone to the particles are shown in Table 2. There were no significant differences observed between the two biomaterials. The lower $n$ values in the Hap groups were due to specimen loss.

\section{Discussion}

The X-ray diffraction (XRD) pattern of milled Hap was observed to be similar to that obtained from BBM particles. The production of BBM from a bovine source

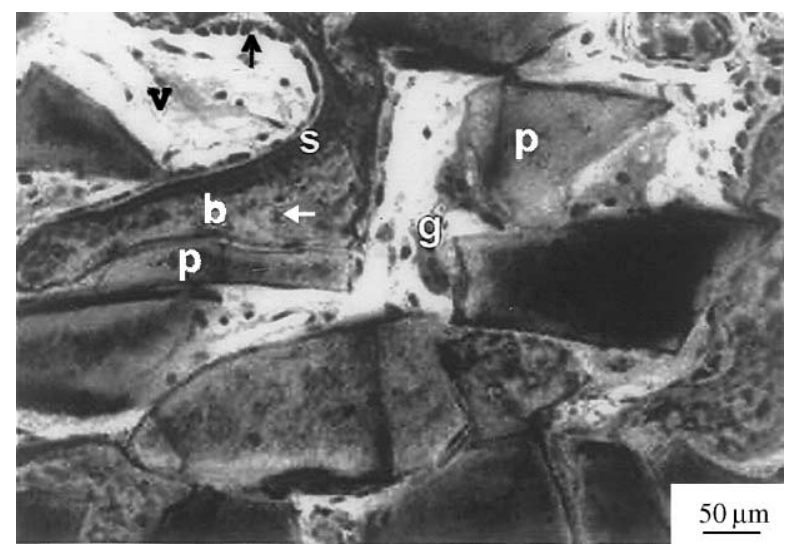

Fig. 2. Photomicrograph showing new bone, b, growing around the osteoconductive particles, $\mathrm{p}: \uparrow=$ osteoblasts, osteocytes, $\leftarrow, \mathrm{s}=$ osteoid tissue, $\mathrm{v}=$ soft tissue and $\mathrm{g}=$ giant cell. Toluidine blue stain.
Table 2

Percentage contact of osseous tissue with implant particles at 5 and 15 post-surgery

\begin{tabular}{lllc}
\hline Observation group & Parameter & \multicolumn{2}{c}{ Observation time } \\
\cline { 3 - 4 } & & 5 weeks & 15 weeks \\
\hline BBM & Median & 46 & 55 \\
& Range & $34-63$ & $18-39$ \\
\multirow{3}{*}{ Hydroxyapatite } & $n$ & 6 & 5 \\
& Median & 36 & 50 \\
& Range & $16-54$ & $11-34$ \\
& $n$ & 4 & 4 \\
\hline
\end{tabular}

produced the mineral constituent of bone, Hap [11]. It has been reported that the bioceramics, BBM and commercial Hap, are chemically $95 \%$ identical [16]. However, the $a$-axis dimension of BBM exceeded that determined in synthetic Hap indicating that BBM contained more carbonate ions.

Compared to the Hap filled defects and the controls, BBM filled defects attained the highest tangential stiffness at 5 weeks post-surgery. The BBM filled defects exhibited properties comparable to those in intact bone earliest, indicating that BBM particles enhanced the healing of cancellous bone defects. As reported by Jarcho [5], synthetic Hap effects defect healing at the same rate as empty defects. Tencer and Johnson [17] reported that when compared to other orthopaedic materials such as stainless steel, $316 \mathrm{~L}$, cell growth was significantly lower on Hap coated surfaces in the first 4 days post-surgery because bone took more time to respond positively to the apatite. This may explain the lower bone contact percentage and lower mechanical properties observed in the Hap filled defects when compared to BBM filled defects. Furthermore, BBM, having been obtained from natural bone possesses more trace elements [18] and carbonates which are reported to enhance osteogenesis [2,19].

Afonso et al. [19] showed that the bioactivity of Hap can be increased by modifying the chemistry of the apatite to form osteoapatites. Osteoapatites consist of oxides of sodium $(\mathrm{Na})$, potassium $(\mathrm{K})$, iron $(\mathrm{Fe})$ and magnesium $(\mathrm{Mg})$. According to the authors, the modification of Hap makes the new bioceramic chemically similar to the mineral part of bone consequently improving its biological performance in vivo. $\mathrm{Na}, \mathrm{K}$ and $\mathrm{Mg}$ enhance ion exchange and bone formation at the implant-bone interface and the provision of calcium and phosphorus in the osseous environment also accelerates the osteogenesis processes as the ions reprecipitate with proteins in the osseous environment. There is evidence in orthopaedics that the efficiency of a calcium phosphate ceramic relates closely to its dissolution properties [19,20]. Adhesion between the implant and 
the new bone is achieved through a reciprocal dissolution/reprecipitation reaction between the bone and the implant through ionic species, $\mathrm{Ca}^{2+}, \mathrm{OH}^{-}, \mathrm{PO}_{4}^{3-}$ carried by the body fluids. When the last ions are deposited a link between new bone and the implant is formed and adhesion is complete, forming a bioactive fixation $[7,19,20]$.

The dissolution of BBM was not determined but there is evidence in the literature that suggests that the bioceramic is not biodegradable [16], and Hap blocks have been observed to maintain their shape in vivo when implanted in humans for 78-109 months [21].

At 5 weeks post-surgery, depending on the porosity of the implant, porous blocks of BBM have been reported [14] to fill extensively with new bone when implanted in rabbits at the same anatomical region as used in the present study. Hing [14] reported that 5 weeks postoperatively the implanted specimens $(4.58 \mathrm{~mm}$ in diameter and $8.76 \mathrm{~mm}$ in depth, and $0.51-0.68 \mathrm{Mg} \mathrm{m}^{-3}$ in density) were infiltrated by de novo bone up to half the implant depth. However, Fujishiro et al. [22] reported that when Bioglass ${ }^{\circledR}$ particles $(100-300 \mu \mathrm{m})$ were implanted for a period of 6 weeks in rabbit femoral defects, $50 \%$ of the defect was filled with new bone compared to $41 \%$ in Hap filled defects. Similarly, in the current work, at 5 weeks after surgery BBM filled defects possessed more bone around the implants than the Hap filled defects and the rates of bone growth mirrored these results. It is postulated that although the percentage bone contact on the two implants was not statistically different, an increase in the population of observations or samples would have resulted in measurements that mirrored the biomechanical properties. Kühne et al. [23] observed that at 12 weeks post-surgery, $6 \mathrm{~mm}$ empty defects had almost completely healed. In this study all the defects exhibited stiffness values that mirrored those of the intact bone only at 15 weeks postsurgery.

Hap and BBM particles were biocompatible and osteoconductive. Berger et al. [24] reported that ideal alloplastic materials for bone replacement should biodegrade, consequently new functional bone will replace it restoring the natural architecture of bone. In the current work, there was no evidence of material degradation.

\section{Conclusion}

The biomechanical data strongly suggest that BBM particles may cause rapid bone ingrowth when implanted in the cancellous bone defects. Five weeks postsurgery the biomechanical properties of the implanted defect mirrored those observed in intact bone. Histomorphometric measurements also showed that BBM treated defects had more new bone incorporated with the particulates. The use of commercial Hap did not appear to accelerate the healing process in the defects, as the biomechanical properties of the Hap filled defects were comparable to those of the empty control defects. In view of the fact that BBM is derived from a biological system, more work is required to mimic its effects, thus completely eradicating any possible inherent risks of antigen transmission. It is evident that even in carefully harvested bone tissues, some tissue is occasionally not suitable for use [25]. Sugihara et al. [25] reported that out of 137 allograft bone grafts harvested for donation during arthroplasty, $31 \%$ were not suitable for implantation although both the European Association of Musculo-Skeletal transplantation and the American Association of Tissue Banks guidelines were observed.

\section{Acknowledgements}

The Beit Trust and the ORS for their support of MTM and EPSRC for the provision of the core grant of the IRC in Biomedical Materials. Dr. K.A. Hing is also acknowledged for supplying the BBM.

\section{References}

[1] Wheeler DL, Stokes KE, Park HM, Hollinger JO. Evaluation of particulate Bioglass ${ }^{\circledR}$ in rabbit radius ostectomy model. J Biomed Mater Res 1997;35:249-54.

[2] Constantz BR, Ison IC, Fulmer MT, Poser RD, Smith ST, VanWagoner M, Ross J, Goldstein SA, Jupiter JB, Rosenthal DI. Skeletal repair by in situ formation of the mineral phase of bone. Science 1995;267:1796-8.

[3] Flautre B, Pasquier G, Blary MC, Anselme K, Hardouin P. Evaluation of hydroxyapatite powder coated with collagen as an injectable bone substitute: microscopy study in rabbit. J Mater Sci: Mater Med 1996;7:63-7.

[4] Oonishi H, Kushitani S, Yasukawa E, Iwaki H, Hench LL, Wilson J, Tsuki E, Sugihara T. Particulate Bioglass ${ }^{\circledR}$ compared with hydroxyapatite as a bone graft substitute. Clin Orthop Rel Res 1997;334:316-25.

[5] Jarcho M. Calcium phosphate ceramics as hard tissue prosthetics. Clin Orthop Rel Res 1981;157:257-78.

[6] LeGeros RZ. Biology and synthetic apatite. In: Brown PW, Constantz B, editors. Hydroxyapatite and related materials. Boca Raton, FL: CRS Press, 1994. p. 3-28.

[7] Ganeles J, Listgarten MA, Evian CI. Ultrastructure of durapatiteperiodontal tissue interface in human intrabony defects. J Periodontol 1986;57:133-40.

[8] Lavernia C, Schoenung JM. Calcium phosphate ceramics as bone substitutes. Bull Am Ceramic Soc Ceramic Bull 1991;70:95-100.

[9] Ravaglioli A, Krajewski A. A historical and philosophical outline and prospects for the application of biomaterials. In: Bioceramics: materials properties applications. London: Chapman and Hall, 1992. p. $1-15$.

[10] Best S, Sim B, Kayser M, Downes S. The dependence of osteoblastic response on variations in the chemical composition and physical properties of HA. J Mater Sci: Mater Med 1997; 8:97-103. 
[11] Gierse H, Donath K. Reactions and complications after the implantation of endobon including morphological examination of explants. Arch Orthop Trauma Surg 1999;119:349-55.

[12] Yaszemski MJ, Payne RG, Hayes WC, Langer R, Mikos AG. Evolution of bone transplantation: molecular, cellular and tissue strategies to engineer human bone. Biomaterials 1996;17:175-85.

[13] Rhinelander FW. Tibial blood supply in relation to fracture healing. Clin Orthop Rel Res 1974;105:34-81.

[14] Hing KA. Assessment of porous hydroxyapatite for bone replacement. Phd thesis. University of London, UK, 1996.

[15] Devore J, Peck R. Statistics: the exploration and analysis of data. California: Duxbury Press, 1993.

[16] Faucheux C, Bareille R, Rouais F, Amedee J, Liebendorfer A, Dard M. Biocompatibility testing of a bovine hydroxy-apatite ceramic material with the use of osteo-progenitor cells isolated from human bone marrow. J Mater Sci: Mater Med 1994;5:635-9.

[17] Tencer AF, Johnson KD. Biomaterials used in fracture fixation. In: Biomechanics in orthopaedic trauma: bone fracture and fixation. London: Martin Dunitz, 1994. p. 84-115.

[18] Hing KA, Best SM, Bonfield W. Characterization of porous hydroxyapatite. J Mater Sci: Mater Med 1999;10:135-45.
[19] Afonso A, Santos JD, Vasconcelos M, Branco R, Cavalheiro J Granules of osteoapatite and glass-reinforced hydroxyapatite implanted in rabbit tibiae. J Mater Sci: Mater Med 1996;7:507-10.

[20] Doi Y, Shibutani T, Moriwaki Y, Kajimoto T, Iwayama Y. Sintered carbonated apatites as bioresorbable bone substitutes. J Biomed Mater Res 1998;39:603-10.

[21] Yamaguchi K, Hirano T, Yoshida G, Iwasaki K. Degradationresistant character of synthetic hydroxyapatite blocks filled in bone defects. Biomaterials 1995;13:983-5.

[22] Fujishiro Y, Hench LL, Oonishi H. Quantitative rates of in vivo bone generation for Bioglass ${ }^{\circledR}$ and hydroxyapatite particles as bone graft substitute. J Mater Sci: Mater Med 1997;8:649-52.

[23] Kühne JH, Bartz R, Frisch B, Hammer C, Jansson V, Zimmer M. Bone formation in coralline HA. Acta Orthop Scand 1994; 65:246-52.

[24] Berger G, Gildenhaar R, Ploska U. Rapid resorbable, glassy crystalline material on the basis of calcium alkali orthophosphates. Biomaterials 1995;16:1241-8.

[25] Sugihara S, van Ginkel AD, Jiya TU, van Royen BJ, van Diest PJ, Wuisman PIJM. Histopathology of retrieved allografts of the femoral head. J Bone Joint Surg 1999;81-B:336-41. 